\title{
Knowledge, Attitude, and Practice of Livestock Owners and Livestock Assistants towards African Trypanosomiasis Control in The Gambia
}

\author{
Alpha Kargbo $\mathbb{D}^{1,2}$ Edrisa Jawo, ${ }^{2}$ Amien Isaac Amoutchi $\mathbb{D}^{1},{ }^{1}$ Herve Koua, ${ }^{3}$ Rex Kuye, \\ Zainabou Dabre $\left(\mathbb{C}^{1}{ }^{1}\right.$ Abdoulie Bojang, ${ }^{5}$ and Rafael F. C. Vieira $\oplus^{6,7}$ \\ ${ }^{1}$ WASCAL-Graduate Research Program in Climate Change and Biodiversity, Universite Felix Houphouet-Boigny, BP V34, \\ Abidjan, France \\ ${ }^{2}$ Department of Physical and Natural Sciences, University of the Gambia, Brikama Campus, P. O Box 3530, Serrekunda, Gambia \\ ${ }^{3}$ Laboratoire de Zoologie et Biologie Animale, Université de Cocody, 22 BP 582 Abidjan 22, France \\ ${ }^{4}$ Department Public Health and Environmental, School of Medicine and Allied Health Science, University of the Gambia, \\ Brikama Campus, P. O Box 3530, Serrekunda, Gambia \\ ${ }^{5}$ Remot Sensing Department, Ahmadu Bello University, Zaria, Kaduna, Nigeria \\ ${ }^{6}$ Vector-Borne Diseases Laboratory, Department of Veterinary Medicine, Universidade Federal do Paraná, Curitiba, PR, Brazil \\ ${ }^{7}$ Global One Health Initiative (GOHi), The Ohio State University, Columbus, OH, USA
}

Correspondence should be addressed to Alpha Kargbo; akargbo@utg.edu.gm

Received 9 September 2021; Revised 21 December 2021; Accepted 7 January 2022; Published 24 January 2022

Academic Editor: Lizandra Guidi Magalhães

Copyright ( 2022 Alpha Kargbo et al. This is an open access article distributed under the Creative Commons Attribution License, which permits unrestricted use, distribution, and reproduction in any medium, provided the original work is properly cited.

Background. In Africa, it has been estimated that 50 million cattle and 70 million sheep and goats are at risk of animal African trypanosomiasis, and three million cattle die annually. Methods. This study was conducted in all the regions of The Gambia except Kombo Saint Mary Island (Banjul). Structured questionnaires were administered to 440 randomly selected livestock owners and 23 livestock assistants, and 7 focus group discussions were held for both livestock owners and livestock assistants. The data were analyzed mainly using descriptive statistics and content analysis methods. Results. A total of $94.5 \%$ and $75 \%$ of livestock owners reported having seen tsetse and horse flies, respectively, while $100 \%$ of livestock assistants reported having seen tsetse flies. Forty-seven percent of the livestock owners indicated a positive attitude toward control measures, while $42 \%$ of them had no idea how to control tsetse flies. On the other hand, 57\% of livestock assistants believe that tsetse and horse flies are the main reasons why AAT is still in their community. There was a statistically significant difference between all the respondents' characteristics and the practices done by livestock owners to prevent AAT vectors from biting their animals. Conclusion. This study shows that trypanosomiasis is still a major problem for livestock health and production in The Gambia, and it requires disease and vector control.

\section{Background}

African animal trypanosomiasis (AAT) is a neglected zoonotic parasitic disease caused by protozoans of the genus Trypanosoma $[1,2]$, and it causes important economic losses of approximately 4.5 billion US dollars per year [3] as a result of direct (mortality, production losses, costs of pro- phylactic, and curative trypanocidal drugs) and indirect losses due to crop spoilage and agricultural worker involvement (deficiency of animal protein diets) [4, 5]. Tsetse flies of the genus Glossina and horse flies of the genus Tabanidae are the main vectors for trypanosomes $[2,6]$. In humans, the disease is known as sleeping sickness or human African trypanosomiasis (HAT), caused by Trypanosoma brucei 
gambiensis and Trypanosoma brucei rhodesiense [6, 7]. In livestock, the disease is known as "nagana" or AAT and is widespread across sub-Saharan Africa [2, 8].

In Africa, it has been estimated that 50 million cattle and 70 million sheep and goats are at risk of AAT, and three million cattle die annually [9]. Livestock rearing in Africa has mainly affected the health, livelihoods, and environment of African people. In many regions of the continent, the demand for livestock products has surpassed domestic production. This demand is expected to be fueled further by population growth, urbanization, and income growth in all African nations [10-12]. Trypanosoma control and prevention can only be attained through vector control by regular dipping of animals in chemicals since vaccine production has not yet been achieved [12]. Moreover, Diminazene aceturate and Isometamidium chloride have been used to cure trypanosomiasis for the past three decades, and there is a possibility that there could be some cases of resistance to these drugs $[11,12]$.

In The Gambia, AAT affects livestock productivity, with equids being very vulnerable [13-15]. The West Africa Livestock Innovation Center (WALIC), through the Ministry of Agriculture and the Horse and Donkey Trust Fund (HDTF), is the two institutions making some effort to control trypanosomiasis in The Gambia. Since there is no available vaccine for trypanosomiasis, WALIC has attempted to select and genetically improve indigenous trypan-tolerant breeds such as N'dama and Zebu cattle to control the incidence of trypanosomiasis in the country and neighboring countries [15]. Zebu cattle are more productive in terms of meat and milk production, although more vulnerable to AAT than N'dama cattle, and they cannot survive for long in both the Central River Region (CRR) and Lower River Region (LRR), regions highly infested with tsetse flies [15]. HDTF has been more active in curing trypanosomiasis-related cases in livestock animals, especially in equids across the country [16]. Currently, there is no official AAT vector control program in The Gambia. Accordingly, the study is aimed at evaluating the knowledge, attitude, and practice (KAP) of livestock owners and livestock assistants toward the AAT control in The Gambia.

\section{Materials and Methods}

2.1. Study Area. The Gambia is the smallest country in mainland Africa and is located in West Africa. It consists of seven administrative regions and one independent city called Banjul (Figure 1). Among the districts selected for this study, the Kanifing Municipal Council and Banjul were the only districts located in the urban area. Participants were chosen randomly from sixteen districts out of 46 districts in The Gambia.

2.2. Study Design and Sampling Technique. A cross-sectional survey was conducted from October 2020 to January 2021 to assess and compare the KAP regarding AAT in The Gambia using a standardized questionnaire $[11,16]$ and focus group discussion (FGD).
The sample size was calculated by Yamane [17] based on an estimated number of 724,952 livestock owners in The Gambia [18] with a level of precision of $0.05 \%$. Thus, the minimum sample size required to detect a difference with a $95 \%$ confidence level of $5 \%$ was estimated as $n=440$ participants. Two districts and one village per district were randomly selected for each region in The Gambia. A list of all livestock owners was obtained from the veterinary service office in the districts under study. The names of the 440 livestock owners (351 males and 89 females) evaluated were randomly selected from the lists provided by the livestock officer serving in each region. Additionally, 23 livestock assistants were also interviewed. A total of seven FGD were evaluated, five for livestock owners and two for livestock assistants.

2.3. Inclusion and Exclusion Criteria. All inhabitants $>18$ years, residing in the specified region for $>36$ months, and able to communicate were considered eligible for the study.

2.4. Method of Data Collection. A standardized questionnaire was developed based on a previous study [12, 19]. The questionnaire comprised 17 questions that were divided into four categories: (1) sociodemographic characteristics; (2) knowledge on the vectors, clinical signs, transmission, and control of trypanosomiasis; (3) economic impact of trypanosomiasis; (4) attitude towards prevention of trypanosomes; and (5) practices regarding trypanosome prevention.

2.5. Data Analysis. The data were entered into the Microsoft Excel software, and either Chi-square or Fisher's exact test was used to assess differences in the proportions of individual variables using Statistical Package for Social Sciences (SPSS) version 25 (IBM Corp., Armonk, NY, USA), and binary logistic regression was used to determine the association between the explanatory variable, and knowledge of vectors was implemented using the $\mathrm{R}$ 3.6.3 software. The results were considered significant when $P \leq 0.05$. The correlation coefficient was used to describe the correlation between knowledge, attitude, and practice regarding AAT.

\section{Results}

3.1. Livestock Owners and Livestock Assistants' Profile. A total of $351 / 440$ (80\%) livestock owners were male between 40 and 49 years old $(132 / 351 ; 37.6 \%)$, while $21 / 23(91.3 \%)$ livestock assistants were male between 18 and 29 years old $(7 / 21 ; 30.4 \%)$. Tables 1 and 2 summarize the profile for both groups.

The majority of livestock owners raised only cattle (195/ $440 ; 44.3 \%)$ and cattle and small ruminants (147/440; $33.4 \%)$, followed by cattle and equids $(47 / 440 ; 10.7 \%)$ and cattle, small, ruminants and equids (51/440; 11.6\%). Herd sizes varied from 1 to 50 (225/440; 55.1\%), 51 to 100 (138/ $440 ; 31.3 \%), 101$ to $150(53 / 440 ; 12.0 \%)$, and >150 (24/440; $5.45 \%)$.

3.2. Knowledge of Vectors and Trypanosomiasis. A total of $416 / 440(94.5 \%)$ livestock owners reported the occurrence of tsetse flies, 330/440 (75\%) reported horse flies, and all 


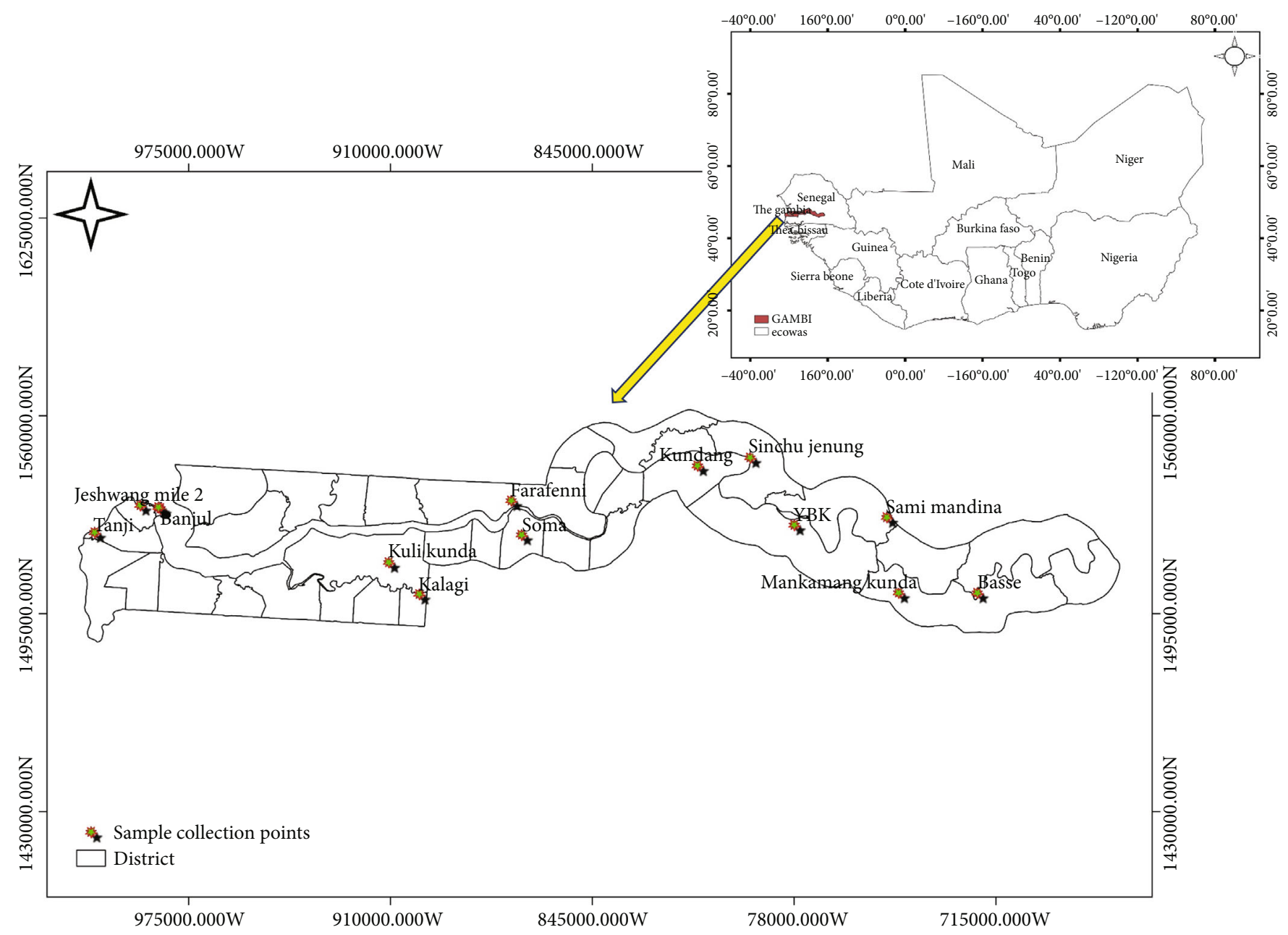

Figure 1: Map of The Gambia showing its position in West Africa and the location of the present study. The figure was generated and modified using ArcGIS 9.

livestock assistants reported the occurrence of AAT vectors. Livestock owners reported that AAT vectors are well known in their local language as follows: tsetse flies are known as "Kosse" in Wolof, "Joloh" in Mandinka, and "Kaifeh" in Fula, while horse flies are also known as "Kusigi" in Wolof, "Sue Joloh" in Mandinka, and "Daaso" in Fula. Furthermore, AAT is known the Wolofs as "Toi" in horses and "Darsoh" in other livestock, "Koojah" in Mandinka, and "Darsoh" in Fula. Respondents' knowledge of tsetse flies was significantly influenced by all their demographic variables. The results from the binary logistic regressions showed a positive relationship between ethnic group $(P \leq 0.01)$, gender $(P=0.015)$, age $(P=0.035)$, occupation $(P=0.04)$, and qualification $(P \leq 0.001)$ and knowledge of tsetse flies. The respondents' knowledge of the occurrence of horse flies was influenced by their age $(P=0.001)$, ethnic group $(P \leq 0.001)$, and qualification $(P \leq 0.001)$ (Table 3$)$.

In FGD, participants claimed the occurrence of tsetse flies in the bushes near their community, in animals' stalls, and generally when livestock was drinking at the well. A total of $411 / 440(93.4 \%)$ and $325 / 440(81.36 \%)$ livestock owners reported the occurrence of tsetse and horse flies in their communities, respectively. Additionally, 358/440
(81\%) livestock owners reported knowing that tsetse flies transmit Trypanosoma, while 286/440 (65\%) reported that their animals had been previously diagnosed with trypanosomiasis. Although 410/440 (93.18\%) livestock owners had access to veterinary practitioners, only 110/440 (25\%) reported previously collected blood samples to diagnose Trypanosoma spp. in their animals. When livestock assistants were interviewed, 13/23 (57\%) reported that they conducted a microscopy laboratory diagnosis of Trypasonoma spp.

From the 440 livestock owners, the clinical signs of AAT described were sluggishness (410; 93\%), loss of weight (330; $75 \%)$, low productivity $(59 ; 13 \%)$, intermittent fever (120; $27 \%)$, and death (425; 97\%). Livestock assistants reported having good knowledge of the clinical signs of AAT, including loss of weight $(12 ; 52 \%)$, anemia $(11 ; 48 \%)$, pale mucous membrane $(7 ; 30 \%)$, abortion $(3 ; 13 \%)$, nervous disorder $(8$; $35 \%)$, rough coat $(9 ; 39 \%)$, weakness $(9 ; 39 \%)$, eye discharge $(8 ; 35 \%)$, fever $(8 ; 35 \%)$, death $(1 ; 4 \%)$, elasticity of skin (9; $2 \%)$, and swollen vulva or tsetse $(4 ; 17 \%)$. There was a statistically significant difference between respondents' characteristics and whether they knew the disease called trypanosomiasis (Table 4). 
TABle 1: Sociodemographic profile of livestock owners from The Gambia, 2021

\begin{tabular}{|c|c|c|}
\hline Characteristics & $\begin{array}{c}\text { Frequency }(n=440 \\
)\end{array}$ & $\begin{array}{c}\text { Percentage } \\
(\%)\end{array}$ \\
\hline \multicolumn{3}{|l|}{ Sex } \\
\hline Male & 351 & 80 \\
\hline Female & 89 & 20 \\
\hline \multicolumn{3}{|l|}{ Age } \\
\hline $0-29$ & 57 & 13 \\
\hline $30-39$ & 91 & 20.7 \\
\hline $40-49$ & 132 & 30 \\
\hline $50-59$ & 64 & 14.5 \\
\hline $60-69$ & 60 & 13.6 \\
\hline$>70$ & 36 & 8.2 \\
\hline \multicolumn{3}{|l|}{ Qualification } \\
\hline Primary & 111 & 25.2 \\
\hline Secondary & 49 & 11.1 \\
\hline Tertiary & 9 & 2.3 \\
\hline Quranic education & 124 & 28.2 \\
\hline None & 147 & 33.2 \\
\hline \multicolumn{3}{|l|}{ Main occupation } \\
\hline Herdsmen & 220 & 50 \\
\hline Crop farming & 19 & 4 \\
\hline Livestock rearing & 124 & 28 \\
\hline $\begin{array}{l}\text { Crop and livestock } \\
\text { farming }\end{array}$ & 4 & 1 \\
\hline Petty trading & 73 & 17 \\
\hline \multicolumn{3}{|l|}{ Region } \\
\hline WCR & 15 & 3.4 \\
\hline LRR & 75 & 17 \\
\hline NBR & 75 & 17.3 \\
\hline CRR-S & 56 & 12.8 \\
\hline CRR-N & 111 & 25.2 \\
\hline URR & 108 & 24.3 \\
\hline
\end{tabular}

WCR: West Coast Region; LRR: Lower River Region; NBR: North Bank Region; CRR-S: Central River Region-South; CRR-N: Central River Region-North; URR: Upper River Region.

3.3. Attitude to Trypanosomiasis. A total of $251 / 440$ (57\%) livestock owners reported that the presence of tsetse flies is the reason why AAT is still prevalent in their community, while $101 / 440(23 \%)$ reported that it is due to the nearby river and $9 / 440(2 \%)$ to the presence of wild animals in their forest. However, all livestock assistants reported that AAT is prevalent in The Gambia because of the presence of the main vectors and lack of official control measures to mitigate the disease in the country.

3.4. Practice to Prevent Insect Biting Livestock Animals. A total of 209/440 (47\%) livestock owners reported the use of chemicals to control tsetse/horse flies from biting their animals, 9/440 (2\%) used resistant breeds, 6/440 (1\%) cleared bushes around the compound, 13/440 (3\%) reported the use of all of the above control measures, and 22/440 (5\%)
TABLE 2: Demographic profile of livestock assistants from The Gambia, 2021.

\begin{tabular}{lcc}
\hline Characteristics & Frequency $(n=23)$ & Percentage (\%) \\
\hline Sex & 21 & 91 \\
Male & 2 & 9 \\
Female & & \\
Age & 7 & 30.4 \\
$18-29$ & 6 & 26.1 \\
$30-39$ & 6 & 26.1 \\
$40-49$ & 3 & 13 \\
$50-59$ & 1 & 4.3 \\
$>60$ & & \\
Region & 5 & 22 \\
KMC & 3 & 13 \\
WCR & 3 & 13 \\
URR & 3 & 13 \\
LRR & 3 & 13 \\
NBR & 3 & 13 \\
CRR-N & 3 & 13 \\
CRR-S & 3
\end{tabular}

WCR: West Coast Region; LRR: Lower River Region; NBR: North Bank Region; CRR-S: Central River Region-South; CRR-N: Central River Region-North; URR: Upper River Region.

reported that AAT was impossible to control. Moreover, $194 / 440$ (44\%) livestock owners reported that they had no idea of how to control tsetse/horse flies. Sociodemographic variables and practices of livestock owners to control vectors from biting their animals in The Gambia are summarized in Table 5.

3.5. Impact of Trypanosomiasis on Livestock Owners. A total of $370 / 440(84 \%)$ livestock owners reported that the cost to treat one infected animal with trypanosomiasis is US\$ 2, and if they are to use prophylaxis, the cost is usually US\$ 4 per cattle. This was also confirmed by the FGDs for both respondent groups.

\section{Discussion}

In the present study, $94.5 \%$ and $75 \%$ of the livestock owners had knowledge about tsetse and horse flies, respectively, and $100 \%$ livestock assistants reported the occurrence of these vectors in their communities and stations, in agreement with previous studies [12, 19-21]. Tsetse flies are known as "Joloh" in Mandinka, "Kosse" in Wolof, and "Kaifeh" in Fula, while horse flies are known as "sue joloh" in Mandinka, "kusigi" in Wolof, and "Daaso" in Fula. During the FGD, livestock owners were well informed about the presence of biting flies in their communities. Most of the respondents described differentiating tsetses from house flies as annoying insects that usually greatly disturb animals. A livestock owner in one of the FGD reported that "Whenever we see an animal is running without anything pursuing it or making a groaning noise most of the times is either tsetse or other flies which usually bites them." However, most of the 
TABLE 3: Association between sociodemographic variables and knowledge of African animal trypanosomiasis vectors in The Gambia, 2021.

\begin{tabular}{lcccc}
\hline & $\begin{array}{c}\text { Knowledge of tsetse } \\
\text { flies } \\
\text { Coefficient } \\
\text { standard error }\end{array}$ & \multicolumn{3}{c}{$\begin{array}{c}\text { Knowledge of horse flies } \\
\text { Coefficient } \\
\text { standard error }\end{array}$} \\
\hline Ethnic group & 0.509 & $0.01^{*}$ & 0.343 & $\leq 0.001^{* *}$ \\
& $(0.199)$ & & $(0.105)$ & \\
Gender & 1.222 & $0.015^{*}$ & 0.187 & 0.55 \\
Age & $(0.507)$ & & $(0.311)$ & \\
Occupation & -0.355 & $0.035^{*}$ & 0.266 & $\leq 0.001^{* *}$ \\
& $(0.168)$ & & $(0.079)$ & \\
Qualification & -0.421 & $0.04^{*}$ & -0.104 & 0.20 \\
& $(0.204)$ & & $(0.082)$ & \\
& -0.402 & $0.001^{* *}$ & -0.346 & $\leq 0.001^{* *}$ \\
& $(0.146)$ & & $(0.073)$ & \\
\hline
\end{tabular}

${ }^{*} P<0.05 ;{ }^{* *} P<0.01$.

livestock owners (409/440, 93\%) also reported that these vectors are larger and have a longer mouth part than house flies and can even bite human beings. This classification made it difficult for them to be able to differentiate between tsetse or house flies and/or other similar insects, although $75 \%$ of livestock owners describe horse flies as "flies with big head and some have colored green or red eyes," similar to previous studies conducted in Tanzania [12] and Uganda [22]. In those studies, the members of the community classified these vectors as "annoying insects which bites both humans their animals" $[12,22]$. Herein, livestock owners and assistants also indicated that these vectors are highly prevalent in The Gambia, and they are well known to be the vector of AAT and HAT in the country.

In the present study, AAT was well known by livestock owners and assistants. During FGD, livestock owners described AAT as a disease similar to malaria in livestock $(81 \%)$, while others described it as being a disease that is caused by hunger (19\%). According to livestock owners and assistants, AAT is one of the main hindrances to livestock production and advancement in The Gambia. This fact might be due to the pathogenicity seen in cattle and the understanding that bush, water, and forests, which are favorable habitants for Trypanosoma spp. infection by these vectors, especially in non-N'dama breeds of cattle. Similarly, our data are in agreement with previous studies that ranked AAT as the most vital limitation to cattle production in East Africa [21, 23, 24], and previous studies have also shown that livestock farmers have strongly reported that AAT is the major problem for livestock productivity and agricultural development in Ethiopia [24, 25] and in Kenya [21].

Herein, $93 \%$ of livestock owners and $100 \%$ of livestock assistants showed a comparatively good understanding of the clinical signs of bovine trypanosomiasis. Our data agree with the findings previously reported in other countries in Africa [24, 26, 27]. However, 93\% of livestock owners reported that they had access to livestock assistants' officers, and most of them (66\%) reported that their animals had been previously infected by Trypanosoma spp. Furthermore, one of the FGDs with livestock assistants reported that the Department of Livestock Services employs only three qualified veterinary doctors, with approximately 80 livestock assistants serving in all administrative regions in The Gambia. This lack of more qualified veterinarians usually hampered veterinary service delivery in the country. However, $75 \%$ of livestock assistants reported that AAT diagnosis is performed based on judgmental and not clinical factors. It was also revealed in FGD that there is only one functional government-owned veterinary laboratory situated at Abuko (urban area) in The Gambia, which makes conducting laboratory analysis difficult in the rural area, even though WALI and HDTF try to complement the effort of The Gambia government by providing veterinary services to infected animals within CRR, LRR, and WD.

Sex $(P=0.008)$, ethnic group $(P \leq 0.001)$, region $(P \leq 0.001)$, and education level $(P \leq 0.001)$ were among the main factors that significantly influenced livestock owners' knowledge of AAT in The Gambia (Table 4). Livestock owners and livestock assistants showed decent attitudes toward AAT. This study agrees with a similar finding in Senegal [28], who also showed that farmers had positive attitudes toward tsetse flies and trypanosomiasis.

Herein, livestock assistants reported that they mainly use Diminazene aceturate, trypamidium, and Isometamidium chloride (Veridium) to treat sick animals suspected of AAT, with trypamidium (Samorin) being usually used as prophylaxis (data not shown). According to one FGD, livestock owners occasionally use the abovementioned drugs to treat their animals suspected of AAT even though they do not have any formal training on drug administration. They do so simply because they try to avoid the cost of paying extra for the treatment of their sick animals if they are to call a livestock assistant. However, the high frequency of trypanocidal application coupled with the report of selfpreparation and injection of the drugs by some livestock owners shows that there is a high risk of possible development of trypanocidal resistance in The Gambia. The frequent act of treating unconfirmed trypanosomiasis cases with trypanocidal certainly leads to the development resistance of Trypanosoma species [21, 24, 28]. On the other hand, $47 \%$ of livestock owners reported that they applied chemicals to their animals to prevent tsetse bites. The present study agrees with a previous study performed in Tanzania [19], who reported that farmers practice dipping animals in chemicals to prevent tsetse flies from biting animals in communities neighboring Serengeti National Park Tanzania. "In the evenings, we light a fire near the animal stalls to keep biting insects at bay, and during the day, we dress our animals' limbs to keep insects at bay, especially if they have a wound on that limb" (FGD). However, $42 \%$ of livestock owners reported that they had no idea on what to do to prevent these vectors from biting their animals. Most livestock owners reported that "Whenever we suspect our animals of having trypanosomiasis, we feed them with Mahogany leaves combined with salt or Detarium sengalense" (FGD). 
TABLE 4: Characteristics of livestock owners and knowledge of African animal trypanosomiasis in The Gambia, 2021.

\begin{tabular}{|c|c|c|c|c|}
\hline Characteristics & $\begin{array}{l}\text { Do you know the disease called trypanosomiasis }(n=440) \\
\text { Yes }\end{array}$ & Frequency (\%) & $X^{2}$ & $P$ value \\
\hline Sex & & & 15.74 & $0.008^{* *}$ \\
\hline Male & 261 & 59 & & \\
\hline Female & 56 & 13 & & \\
\hline Age & & & 48.168 & $0.004^{* *}$ \\
\hline $0-29$ & 39 & 9 & & \\
\hline $30-39$ & 64 & 15 & & \\
\hline $40-49$ & 102 & 23 & & \\
\hline $50-59$ & 42 & 10 & & \\
\hline $60-69$ & 44 & 10 & & \\
\hline$>70$ & 26 & 6 & & \\
\hline Ethnic group & & & 50.185 & $\leq 0.001^{* *}$ \\
\hline Mandinka & 147 & 33 & & \\
\hline Fula & 99 & 23 & & \\
\hline Jola & 16 & 4 & & \\
\hline Wolof & 53 & 12 & & \\
\hline Others & 2 & 0.5 & & \\
\hline Education & & & 74.361 & $\leq 0.001^{* *}$ \\
\hline Primary & 74 & 17 & & \\
\hline Secondary & 38 & 9 & & \\
\hline Tertiary & 8 & 2 & & \\
\hline Madarasa & 101 & 23 & & \\
\hline None & 96 & 22 & & \\
\hline Region & & & 171.25 & $\leq 0.001^{* *}$ \\
\hline WCR & 15 & 3 & & \\
\hline LRR & 57 & 13 & & \\
\hline NBR & 61 & 14 & & \\
\hline CRR-S & 40 & 9 & & \\
\hline CRR-N & 80 & 18 & & \\
\hline URR & 64 & 15 & & \\
\hline Occupation & & & 73.248 & $\leq 0.001^{* *}$ \\
\hline Herdsmen & 162 & 37 & & \\
\hline Crop farming & 14 & 3 & & \\
\hline Livestock farming & 83 & 19 & & \\
\hline Crop and livestock farming & 3 & 0.7 & & \\
\hline Others & 55 & 13 & & \\
\hline
\end{tabular}

Others include fisher forks, housewives, craft workers, and petty traders. WCR: West Coast Region; LRR: Lower River Region; NBR: North Bank Region; CRRS: Central River Region-South; CRR-N: Central River Region-North; URR: Upper River Region. ${ }^{*} P<0.05 ;{ }^{* *} P<0.01$.

The only government-led program to control trypanosomiasis in The Gambia is financing the activities of the WALI. It is also worth noting that a livestock assistant noted in another FDG that "Through WALI, local breeds are known as N'dama cattle and Jallonke sheep which are resistant to trypanosomiasis are usually crossed breed with other breeds and the animals with higher resistance ability are usually sold to farmers living in the high trypanosomiasis prevalent zones in The Gambia" (FGD). On the other hand, livestock assistants usually advise farmers to keep animals in secure houses, use insect dipping, grazing animals in open fields rather than bush areas, and light a fire at night to prevent vectors from biting livestock (FGDs). Respondents' characteristics and the practices done by livestock owners to prevent vectors from biting their animals were statistically associated: sex $(P=0.013)$, age $(P=0.014)$, ethnic group $(P \leq 0.001)$, region $(P \leq 0.001)$, occupation $(P=0.001)$, and education level $(P<0.001)$.

This study shows that livestock farmers in all regions and of all ages are aware of AAT and how to control the disease in their animals. This finding is similar to previous studies by Barrow et al. [29], who also reported that there 


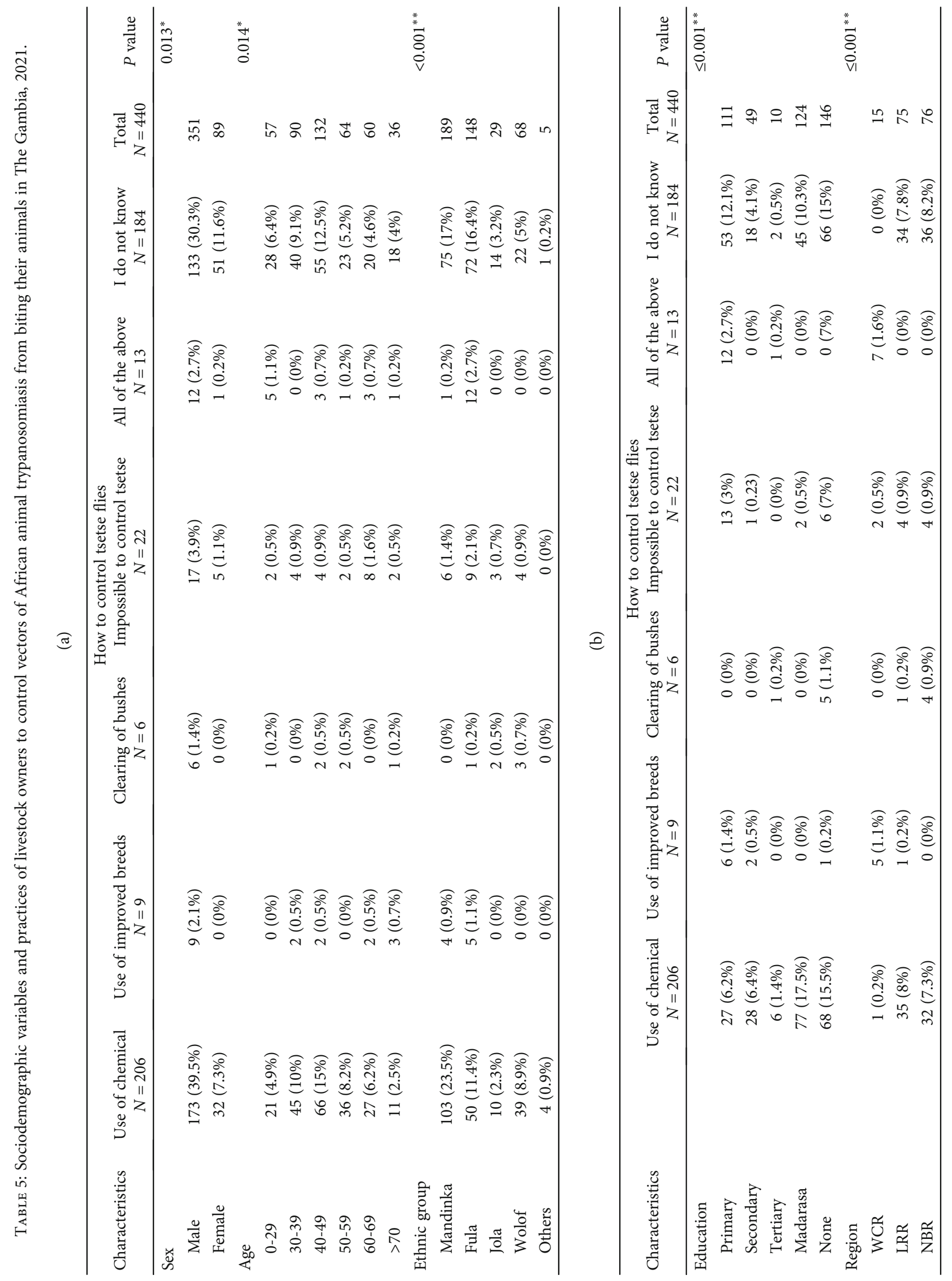




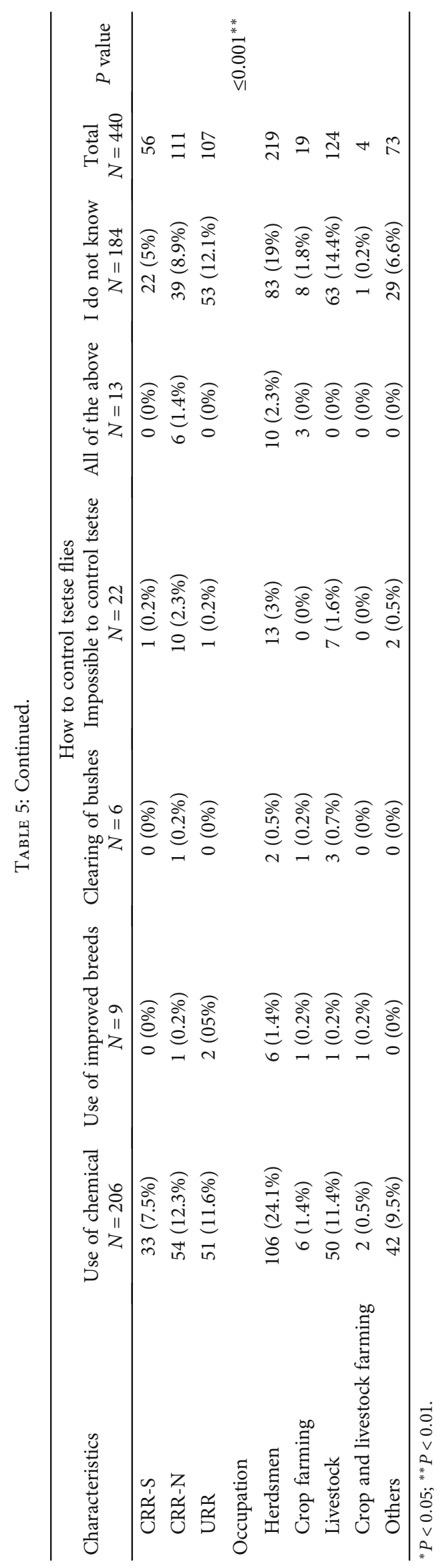


was a higher significance of age and gender in practices that control and prevent schistosomiasis in The Gambia. Finally, $84 \%$ of livestock owners reported expending US\$ 2 and $16 \%$ expending US\$ 3 to treat one of their cattle suspected of having trypanosomiasis depending on the severity of the animal's ailment. The burden of treatment for this disease further helps to impoverish livestock owners in The Gambia. This finding corroborates with previous studies in Kenya [7, 21], which reported that AAT has significantly affected the settlements and economic development of farmers in most countries in Africa, particularly those south of the Sahara Desert, in which The Gambia is definitely not an exception.

\section{Conclusion}

The survey conducted on the knowledge, attitude, and practice of livestock owners and livestock assistants on the occurrence of trypanosomiasis in The Gambia has provided us with important information on the status of AAT, and the KAP of livestock owners and livestock assistants affects disease control. Livestock owners and livestock assistants also recognized that tsetses are associated with trypanosomiasis and had good knowledge of the clinical signs of AAT and its impact on the livelihood and well-being of cattle as well as on the owners. As a result, we urge that more research to be conducted in The Gambia to establish the efficiency of routinely used trypanocidal drugs. Finally, we urge that The Gambia government and other stakeholders invest in the development of DLS staff's human resource capacity, as well as the future development of all veterinary laboratories in the country, to ensure the appropriate diagnosis of AAT.

\section{Abbreviations}

$\begin{array}{ll}\text { AAT: } & \text { Animal African trypanosomiasis } \\ \text { HAT: } & \text { Human African trypanosomiasis } \\ \text { KAP: } & \text { Knowledge attitude practice } \\ \text { FGD: } & \text { Focus group discussion } \\ \text { WALIC: } & \text { West Africa Livestock Innovative Center } \\ \text { HDTF: } & \text { Horse and Donkey Trust Fund } \\ \text { CRR-S: } & \text { Central River Region-South } \\ \text { CRR-N: } & \text { Central River Region-North } \\ \text { WCR: } & \text { West Coast Region } \\ \text { LRR: } & \text { Lower River Region } \\ \text { URR: } & \text { Upper River Region } \\ \text { KMC: } & \text { Kanifing Municipal Council. }\end{array}$

\section{Data Availability}

The data will be made available upon request.

\section{Ethical Approval}

This study was permitted by the Ethics Committee of the Ministry of Higher Education Science Research and Technology, The Gambia (reference number AFG 85/272/01).

\section{Consent}

A signed consent form was obtained from the participants.

\section{Conflicts of Interest}

The authors declare that they have no competing interests.

\section{Authors' Contributions}

Ak conceived the project idea. Ak, HK, RK, and RFCV prepared the research instruments. $\mathrm{AK}, \mathrm{AB}, \mathrm{EJ}, \mathrm{AIA}$, and $\mathrm{ZD}$ collected all the necessary data and analyzed and drafted the manuscript. The study was guided and supervised by $\mathrm{HK}, \mathrm{RK}$, and RFCV. AK and RFCV wrote the manuscript. All coauthors reviewed and discussed the results, helped in the interpretation of the results, and contributed to the draft and final manuscript. All authors read and approved the final manuscript.

\section{Acknowledgments}

This study is part of a PhD degree for Alpha Kargbo at the Universite Felix Houphouet-Boigny. Alpha Kargbo was sponsored by a fellowship from the West African Climate Change and Adapted Land use program through the German Federal Ministry for Education and Research. The Brazilian National Council of Scientific and Technological Development (CNPq) provided a Research Productivity (PQ) fellowship to Dr. Rafael Vieira (CNPq -313161/20208). The study was funded by the West African Climate Change and Adapted Land Use Program through the German Federal Ministry for Education and Research.

\section{References}

[1] S. J. Black and J. M. Mansfield, "Prospects for vaccination against pathogenic African trypanosomes," Parasite Immunology, vol. 38, no. 12, pp. 735-743, 2016.

[2] N. Hundessa, E. Esrael, H. Fesseha, and M. Mathewos, "Study on prevalence of trypanosomosis in cattle of Sodo Zuriya District, Wolaita Zone, Southern Ethiopia," Journal of Parasitology Research, vol. 2021, Article ID 4472480, 9 pages, 2021.

[3] R. A. Oluwafemi, A. A. Ilemobade, and E. A. O. Laseinde, "The impact of African animal trypanosomosis and tsetse on the livelihood and well-being of cattle and their owners in the BICOT study area of Nigeria," Scientific Research and Essay, vol. 2, pp. 380-383, 2007.

[4] T. E. E. Angara, A. A. Ismail, and A. M. Ibrahim, "An overview on the economic impacts of animal trypanosomiasis," Global Journal for Research Analysis, vol. 3, pp. 275-276, 2012.

[5] A. Getachew, J. B. Malone, and A. R. Thomson, "Geospatial for cost model for tsetse transmitted animal trypanosomosis in Ethiopia," SINET, Ethiopian Journal of Science, vol. 76, no. 7, pp. 93-94, 2004.

[6] S. M. Samdi, A. O. Fajinmi, J. O. Kalejaye et al., "Prevalence of Trypanosomosis in cattle at slaughter in Kaduna central abattoir," Asian Journal of Animal Sciences, vol. 5, no. 2, pp. 162165, 2011.

[7] M. O. Ngayo, Z. K. Njiru, E. U. Kenya, G. M. Muluvi, E. O. Osir, and D. K. Masiga, "Detection of trypanosomes in small ruminants and pigs in western Kenya: important reservoirs in the epidemiology of sleeping sickness?," Kinetoplastid Biology and Disease, vol. 4, no. 1, pp. 1-7, 2005. 
[8] G. Cecchi, M. Paone, U. Feldmann, M. J. Vreysen, O. Diall, and R. C. Mattioli, "Assembling a geospatial database of tsetse transmitted animal trypanosomosis for Africa," Parasites and Vectors, vol. 7, no. 39, p. 2014, 2014.

[9] International Forum on Advancements in Healthcare, A report for IFAH, Bill and Milinda Gates Foundation Oxford Analytica, 2014.

[10] Food and Agricultural Organization, Strategic reviews of traps and targets for tsetse and African trypanosomiasis, Food and Agricultural Organization (FAO), 2003.

[11] S. Ravel, O. Mediannikov, G. Bossard, M. Desquesnes, G. Cuny, and B. A. Davoust, "A Study on African animal trypanosomosis in four areas of Senegal," Folia Parasitologica, vol. 62, p. 44, 2015.

[12] D. L. Mwaseba and K. J. Kigoda, "Knowledge, attitude, and practices about tsetse control among communities neighbouring Serengeti National Park, Tanzania," Heliyon, vol. 3, article e00324, 2017.

[13] W. F. Snow, T. J. Wacher, and P. Rawlings, "Observations on the prevalence of trypanosomosis in small ruminants, equines and cattle, in relation to tsetse challenge, in The Gambia," Veterinary Parasitology, vol. 66, pp. 1-11, 1996.

[14] P. Starkey and A. Faye, "Animal Traction for Agricultural Development," in Proceedings of the Third Workshop of the West Africa Animal Traction Network Held from 7-12 July 1988, Published by CTA, p. 475, Saly, Senegal, 1990.

[15] A. Kargbo, G. U. Ebiloma, Y. K. E. Ibrahim, G. D. Chechet, M. Jeng, and E. O. Balogun, "Epizootiology and molecular identification of trypanosome species in livestock ruminants in The Gambia," Acta Parasitologica, vol. 66, no. 2, pp. 1-13, 2021.

[16] A. Kargbo and R. A. Kuye, "Epidemiology of tsetse flies in the transmission of trypanosomiasis: technical review of The Gambia experience," International Journal of Biological Science and Chemical Science, vol. 14, no. 3, pp. 1093-1102, 2020.

[17] T. Yamane, Statistics, an Introductory Analysis, Harper and Row, New York, 2nd Ed. edition, 1967.

[18] Gambia Bureau of Statistics, Gambia Bureau of Statistics (GBOS), Integrated Household Survey 2015/16, vol. II, Socioeconomic Characteristics, The Government of The Gambia, Banjul, The Gambia, 2017.

[19] H. B. Magwisha, I. I. Malele, H. S. Nyingilili et al., "Knowledge, attitude and control practices of tsetse flies and trypanosomiasis among agro-pastoralists in Rufiji Valley, Tanzania," Journal of Commonwealth Veterinary Association, vol. 29, pp. 5-11, 2013.

[20] M. A. Gumel, A. Y. Manu, and M. A. Qadeer, "Evaluation of cattle rearer's knowledge, attitude and practice about tsetse fly in Muri district, Taraba state, Nigeria," Bayero Journal of Pure and Applied Sciences, vol. 6, no. 1, pp. 127-131, 2014.

[21] B. W. Muriithi, N. G. Gathogo, N. G. Diiro, M. M. Kidoido, M. N. Okal, and D. K. Masiga, "Farmer perceptions and willingness to pay for novel livestock pest control technologies: a case of tsetse repellent collar in Kwale County in Kenya," PLoS Neglected Tropical Diseases, vol. 15, no. 8, article e0009663, 2021.

[22] V. Kovacic, I. Tirados, J. Esterhuizen et al., "Community acceptance of tsetse control baits: a qualitative study in Arua District, North West Uganda," PLoS Neglected Tropical Diseases, vol. 7, no. 12, p. 12, 2013.
[23] G. J. Rowlands, W. Mulatu, E. Authié, G. D. M. D'Ieteren, S. G. A. Leak, and S. M. Nagda, "Effects of trypanosomosis on reproduction of East African Zebu cows exposed to drugresistant trypanosomes," Preventive Veterinary Medicine, vol. 21, pp. 237-249, 1994.

[24] Z. Seyoum, G. Terefe, and H. Ashenafi, "Farmers' perception of impacts of bovine trypanosomosis and tsetse fly in selected districts in Baro-Akobo and Gojeb river basins, Southwestern Ethiopia," BMC veterinary research, vol. 9, no. 1, p. 214, 2013.

[25] T. Tewelde, G. Abebe, M. C. Eisler et al., "Application of field methods to assess isometamidium resistance of trypanosomes in cattle in western Ethiopia," Acta Tropica, vol. 90, no. 2, pp. 163-170, 2004.

[26] D. Shimelis, A. K. Sangwan, and A. Getachew, "Epidemiology of bovine trypanosomiasis in the Abay (Blue Nile) basin areas of northwest Ethiopia," Revue de Médecine Vétérinaire, vol. 9, no. 3, pp. 151-157, 2005.

[27] S. O. Ohaga, E. D. Kokwaro, I. O. Ndiege, A. Hassanali, and R. K. Saini, "Livestock farmers' perception and epidemiology of bovine trypanosomosis in Kwale District, Kenya," Preventive veterinary medicine, vol. 80, no. 1, pp. 24-33, 2007.

[28] S. Geerts and P. H. Holmes, Drug management and parasite resistance in bovine trypanosomosis in Africa, PAAT Technical and Scientific Series, no. 1, 1998FAO, Rome (Italy), 1998.

[29] A. Barrow, M. Badjie, J. Touray et al., "Knowledge, attitude, and practice of provincial dwellers on prevention and control of schistosomiasis: evidence from a community-based crosssectional study in the Gambia," Journal of tropical medicine, vol. 2020, Article ID 2653096, 9 pages, 2020. 